\title{
COMENTARIO DE JURISPRUDENCIA
}

\section{La declaración de los Lugares de Importancia Comunitaria: un procedimiento administrativo complejo. Reflexiones sobre su recurribilidad}

\author{
María Luisa Amate Ávila
}

Letrada de la Junta de Andalucia

SUMARIO: I.- INTRODUCGIÓN II.- LA PROPUESTA DE LUGARES DE IMPORTANCIA COMUNITARIA 1.- Marco Normativo 2.Sustantividad de la propuesta elaborada por las Comunidades Autónomas: alcance y eficacia 3.- Carácter meramente formal de propuesta que se eleva por parte del Ministerio a la Comisión Europea 4.- Aspectos procedimentales de esta Etapa Primera: cambio normativo III LA APROBACIÓN POR PARTE DE LA COMISIÓN EUROPEA DEL LISTADO DE LUGARES DE IMPORTANCIA COMUNITARIA 1.- Alcance y eficacia de la aprobación por parte de la Comisión Europea 2.Aprobación e ulteriores actualizaciones del Listado de Lugares de Importancia Comunitaria de la región biogeográfica mediterránea 3.- Recurribilidad de la Decisión europea IV DECLARACION DE ZONAS DE ESPECIAL PROTEGCIÓN V.- REFLEXIONES SOBRE LA REGURRIBILIDAD DE LA INCLUSION DE UNOS TERRENOS DENTRO DE UN LUGAR DE IMPORTANCIA GOMUNITARIA

\section{RESUMEN:}

Este trabajo pretende poner de relieve el carácter complejo del procedimiento administrativo previsto para la declaración de un Lugar de Importancia Comunitaria y cómo la existencia de distintas etapas y la intervención en cada una de ellas de diferentes Administraciones dificulta las posibilidades de impugnarla.

ABSTRACT:

This work aims to highlight the complex nature of the administrative procedure for declaring a Site of Community Interest and how the existence of different stages and the fact of involving various administrations hinders the chances of its challenge. 


\section{INTRODUCGIÓN}

Los Lugares de Importancia Comunitaria (en adelante LIC), como ha tenido ocasión de exponer el Tribunal Supremo, entre otras en su sentencia de 11 de mayo de 2009, tienen su origen en la Directiva 92/43/CE de 21 de mayo de 1992, Directiva Hábitats, relativa a la conservación de los hábitats naturales y de la flora y fauna silvestre, que tiene por objeto, según se indica en el epígrafe 1 del artículo 2 "... contribuir a garantizar la biodiversidad mediante la conservación de los hábitats naturales y de la flora y fauna silvestres en el territorio europeo de los Estados miembros al que se aplica el Tratado ", añadiendo en su epigrafe 2 que las medidas que se adopten en virtud de este Directiva tendrán por finalidad "el mantenimiento o el restablecimiento, en un estado de conservación favorable, de los hábitats naturales y de las especies silvestres de la flora y de la fauna de interés comunitario".

Para conseguir este objetivo, la Directiva crea una Red Ecológica Europea, denominada "Natura 2000 " que, de conformidad con lo dispuesto en el artículo 3.1, se formará mediante la inclusión de los siguientes espacios:

A) Los lugares que cuenten con los hábitats naturales y hábitats de especies definidos en los anexos I y II de la Directiva 92/43/CE, que son los ámbitos LIC. Estos lugares han de referirse a las diferentes regiones biogeográficas, y

B) Los lugares o zonas de protección designadas por los Estados miembros en aplicación de la anterior Directiva 79/409/CEE, Directiva de Aves.

Para la formación de la Red Ecológica "Natura 2000" se establece un procedimiento en el que se pueden distinguir tres grandes fases o etapas, siendo la intervención o protagonismo de los Estados miembros y de las Autoridades comunitarias diferente en cada una de ellas.

ETAPA 1: Tiene por objeto la delimitación espacial de los lugares que cuenten con hábitats naturales de interés comunitario de los enumerados en el anexo I y hábitats de especies animales y vegetales de interés comunitarios de las enumeradas en el anexo II, facilitando a la Comisión información sobre aquellos lugares en que, en principio, concurren las requisitos para su declaración como de importancia comunitarias.

Esta primera etapa se caracteriza por la intervención exclusiva de los Estados miembros, por cuanto son ellos los obligados a facilitar a la Comisión una lista en que se contengan los citados lugares (Artículo 4.1.)

Respecto a la forma de cumplir esta obligación, el artículo 4 de la Directiva 
señala que se ha de efectuar mediante la formación de una lista de lugares, acompañado de una información de cada lugar, consistente en mapa del mismo, denominación, ubicación, extensión y demás datos resultantes de la aplicación de los criterios indicados en el anexo III de la Directiva. Esta información se facilitará a la Comisión mediante el modelo de formulario por ella aprobado y el plazo para que cada Estado cumpliera esta obligación era de 3 años.

ETAPA 2. En esta fase, la Comisión Europea, con la ayuda del Centro Temático de la Naturaleza, de la Agencia Europea del Mediante Ambiente y mediante seminarios biogeográficos y reuniones bilaterales, procede a la comprobación de las listas de ámbitos LIC remitidas por los Estados miembros, de cuyo examen puede resultar la insuficiencia o suficiencia de los LIC seleccionados por cada uno de los Estados, debiendo completarse en caso de insuficiencia. Interesa destacar que, en esta fase, la actuación de la Comisión no se limita a una simple validación de las listas de lugares seleccionados por los Estados, sino que es una labor de comprobación, de forma tal que el artículo 5 prevé la posibilidad de modificar esta lista, estableciendo un procedimiento específico de concertación, no superior a 6 meses, entre el Estado miembro y la Comisión a fin de resolver la discrepancia surgida respecto de los lugares que deban figurar en la lista LIC, discrepancia que, en caso de persistir, se resuelve en el sentido de que la "Comisión presentará al Consejo una propuesta relativa a la selección del lugar como lugar de importancia comunitaria". Esta fase finaliza con la aprobación por la Comisión de la lista definitiva de LIC. (Artículo 4.2.)

En esta fase, aunque la resolución definitiva compete a la Comisión, existe una intervención compartida con los Estados miembros para las funciones de comprobación y, en su caso, concertación de los LIC.

ETAPA 3. Se inicia tras la aprobación por la Comisión de los LIC y en ella el protagonismo de los Estados miembros, como en la etapa 1, es exclusivo, pues la aprobación de los LIC hace surgir en los Estados el deber de declarar estos ámbitos como Zonas Especiales de Conservación -ZEG-, en el menor tiempo posible y, en todo caso, en el plazo máximo de 6 años, según previene el artículo 4.4. al establecer que, por medio de la designación de las ZEC, los Estados ". . fijarán las medidas de conservación necesarias que implicarán, en su caso, adecuados planes de gestión, especificos a los lugares o integrados en otros planes de desarrollo, y las apropiadas medidas reglamentarias, administrativas o contractuales, que respondan a las exigencias ecológicas de los tipos de hábitats naturales del Anexo I y de las especies del Anexo II presentes en los lugares.

Por tanto, y en principio, es con posterioridad a la aprobación de los LIC por la Comisión cuando los Estados miembros tienen el deber de concretar el régimen de conservación de cada uno de estos lugares, estableciendo los usos y acti- 
vidades permitidas y prohibidas, delimitando con ello el régimen jurídico de cada uno de ellos.

Nos encontramos así ante un procedimiento complejo en el que, según la etapa a la que se atienda, es una Administración Pública la que actúa, confluyendo en el procedimiento tanto las Autoridades Internas de los Estados Miembros como las Instituciones Comunitarias, siendo tres los hitos fundamentales que marcan las 3 etapas expuestas:

1.- La propuesta de posibles LIC que elevan los Estados Miembros a la Comisión Europea

2.- La decisión de la Comisión Europea de aprobar el Listado de LICs

3.- La aprobación por los Estados Miembros de las normas encaminadas a garantizar la conservación de los valores presentes en los LIC, mediante el establecimiento de un régimen concreto de usos y actividades.

\section{LA PROPUESTA DE LUGARES DE IMPORTANCIA COMU- NITARIA}

\section{Marco Normativo}

Como hemos señalado, la Primera Etapa es la de mera propuesta de los Lugares de Importancia Comunitaria y corresponde a los Estados Miembros.

En el caso de España, en atención al reparto interno de competencias entre el Estado y las Comunidades Autónomas, y habida cuenta las competencias que en materia medioambiental corresponden a estas últimas, esta delimitación especial la realizan las Comunidades Autónomas, que deben elevar su lista al Ministerio de Medio Ambiente para su ulterior proposición a la Comisión Europea.

En cuanto a la regulación de este etapa del procedimiento hay que acudir, en un primer momento, al RD 19997/95 de 7 de diciembre por el que se establecen medidas para contribuir a garantizar la biodiversidad mediante la conservación de los hábitats naturales y de la fauna y flora silvestres y, a través del cual, como señala su Preámbulo, se transpuso la citada Directiva al Derecho Español, en la parte en que sus previsiones no estaban ya contempladas en la Ley 4/89, de 27 de marzo de Conservación de los Espacios Naturales y de la Flora y Fauna Silvestre, pues los principios que inspiraron a redacción de la misma y que figuran en su artículo 2 vienen a ser los mismos que, tres años más tarde, fueron 
recogidos en la citada Directiva, como objeto o finalidad de ésta, si bien, por ese adelanto temporal, hay algunos preceptos de la misma que no formaban parte aún del Derecho español.

Así, en el artículo 4 se disponía que "Los órganos competentes de las Comunidades Autónomas elaborarán en base a los criterios contenidos en el anexo III y a la información cientifica disponible, una lista de lugares que, encontrándose situados en sus respectivos territorios, puedan ser declarados como zonas especiales de conservación, con indicación de los tipos de hábitats naturales de los enumerados en el anexo I y de las especies autóctonas existentes en dichos lugares enumeradas en el anexo II. Estas lista se facilitarán al Ministerio de Agricultura, Pesca y Alimentación que de acuerdo con los criterios de selección que establece el anexo III las propondrá a la Comisión Europea, a través del cauce correspondiente"

Actualmente, es artículo 42.2 de la ley 42/07 de 13 de diciembre, de Patrimonio Natural y Biodiversidad el que aborda esta cuestión, disponiendo: Las Comunidades autónomas elaborarán, en base a los criterios establecidos en el Anexo III y a la información cientifica pertinente, una lista de lugares situados en sus respectivos territorios que puedan ser declarados como zonas especiales de conservación. La propuesta, que indicará los tipos de hábitats naturales y las especies autóctonas de interés comunitario existentes en dichos lugares, se someterá al trámite de información pública.

El Ministerio de Medio Ambiente propondrá la lista a la Comisión Europea para su aprobación como Lugar de Importancia Comunitaria.

Desde el momento que se envíe al Ministerio de Medio Ambiente la lista de los espacios propuestos como Lugares de Importancia Comunitaria, para su traslado a la Comisión Europea, éstos pasarán a tener un régimen de protección preventiva que garantice que no exista una merma del estado de conservación de sus hábitats y especies hasta el momento de su declaración formal. El envío de la propuesta de un espacio como Lugar de Importancia Comunitaria conllevará, en el plazo máximo de seis meses, hacer público en el boletín oficial de la administración competente sus límites geográficos, los hábitats y especies por los que se declararon cada uno, los hábitats y especies prioritarios presentes y el régimen preventivo que se les aplicará.

En ambos preceptos, la norma distingue las competencias que corresponden a las Comunidades Autónomas, de elaboración material de los listados de posibles Lugares de Importancia Comunitaria dentro de sus territorios, del papel que corresponde a la Administración General del Estado, a través del Ministerio competente en materia de Medio Ambiente, de elevar formalmente el conjunto de propuestas recibidas de las distintas Comunidades Autónomas para su aprobación por parte de la Comisión Europea.

Si bien en esta etapa podría apreciarse la distinción de dos actos administra- 
tivos distintos, uno el de propuesta formulado por la Comunidad Autónoma y otro el de elevación de la propuesta por parte del Ministerio, lo cierto es que no resulta en modo alguno equiparable la naturaleza jurídica de uno y otro acto, tal y como analizaremos a continuación.

\section{Sustantividad de la propuesta elaborada por las Comunidades Autónomas: alcance y eficacia}

El Tribunal Supremo, en el Fundamento de Derecho Undécimo de su sentencia de 11 de mayo de 2009, afirmaba la impugnabilidad de la propuesta de la Comunidad Autónoma en base al hecho de que "los Estados miembros (en España, las Comunidades Autónomas) tienen la obligación de adoptar medidas de protección adecuadas para los lugares que figuren en las listas nacionales remitidas a la Comisión, antes incluso de que ésta confecciones sus listas.

(....) la elaboración de las listas por las Comunidades Autónomas no es algo inocuo, algo que no produzca efectos jurídicos y materiales; no es una mera propuesta neutra, sino un acto administrativo que habilita y obliga a la propia Comunidad Autónoma a adoptar "medidas de protección adecuadas" para los lugares incluidos; se trata de un acto que, siendo una propuesta, pone una condición necesaria y suficiente para crear en la Comunidad Autónoma la obligación de adoptar medidas de protección adecuadas, las cuales pueden quizá afectar a ciertos contenidos del derecho de los propietarios de los terrenos incluidos, razón por la cual la elaboración de las listas puede ser impugnada por los interesados al tener un contenido que excede de la pura ordenación o impulso del procedimiento."

La sentencia considera la Propuesta elaborada por la Comunidades Autónomas como un acto con sustantividad propia y, por ello, susceptible de ser impugnado en base a los efectos que de la propuesta se derivan, ya que implica la adopción de medidas de protección respecto de los terrenos propuestos como LIC, desde dicho momento y aunque todavía no se haya producido su declaración como tal.

Así se deduce, sin ninguna duda, de la sentencia del Tribunal de Justicia de las Comunidades Europeas de Luxemburgo, de fecha 13 de Enero de 2005 (Sociedad Italiana Dragaggi y otros, cuestión prejudicial; asunto G-C 117/2003), donde el Tribunal declaró lo siguiente:

"El artículo 4, apartado 5, de la Directiva 92/43/CEE del Consejo, de 21 de mayo de 1992 , relativa a la conservación de los hábitats naturales y de la fauna y flora silvestres, debe interpretarse en el sentido de que las medidas de protección previstas en el articulo 6, apartados 2 a 4, de esta Directiva sólo son obligatorias por lo que respecta a los lugares que, de conformidad con el artículo 4, apartado 2, párrafo tercero, de la citada Directiva, están incluidos en la 
lista de lugares seleccionados como lugares de importancia comunitaria aprobada por la Comisión de las Comunidades Europeas mediante el procedimiento previsto en el artículo 21 de dicha Directiva".

Pero declaró asimismo que, de ello no se desprende que los Estados miembros no deban proteger los lugares a partir del momento en que los proponen, con arreglo al artículo 4-1 de la Directiva, en la lista nacional que se remite a la Comisión, puesto que "En cuanto a los lugares que pueden clasificarse como lugares de importancia comunitaria, que figuran en las listas nacionales remitidas a la Comisión, y, en especial, a los lugares en los que existen tipos de hábitats naturales prioritarios o especies prioritarias, los Estados miembros están obligados a adoptar, en virtud de la Directivas 92/43, medidas de protección apropiadas, visto el objetivo de conservación perseguido por la Directiva, para proteger el interés ecológico pertinente que dichos lugares tienen a nivel nacional'. Esta es una consecuencia que el Tribunal extrae de la propia Directiva 92/43/CEE; por lo tanto, cuando la posterior Ley española 42/2007 dispone en su artículo 42.2, tercer párrafo, que desde el momento en que se envía al Ministerio de Medio Ambiente la lista de los espacios propuestos estos pasarán a tener un régimen de protección preventiva, no está imponiendo algo novedoso, sino insistiendo en un régimen que estaba ya incluido, según el Tribunal, en la propia Directiva.

En consecuencia, como señaló el Tribunal Supremo, la propuesta es un acto de trámite pero cualificado, dado el régimen preventivo de protección que desde la misma resulta de directa aplicación.

No obstante, hay que destacar que la sentencia insiste, especialmente, en descartar que, en el procedimiento de aprobación de los LIC, la actividad realmente sustantiva sea la llevada a cabo por las Comunidades Autónomas al seccionar estos ámbitos en su territorio. Así, no considera correcta la interpretación que trata de minimizar las funciones de la Comisión a la hora de la aprobación, equiparándola erróneamente a funciones de mera comprobación de suficiencia o de simple convalidación de las listas autonómicas.

\section{Carácter meramente formal de propuesta que se eleva por parte del Ministerio a la Comisión Europea}

La Audiencia Nacional, en su sentencia de 23 de septiembre de 2010, por la que se desestima el recurso contencioso administrativo interpuesto contra resolución del Ministerio de Medio Ambiente, por la que se aprueba la "Lista Nacional de Interés Comunitario" del territorio español, aborda la naturaleza y alcance que debe atribuirse a dicho acto, afirmando:

"la clasificación de una finca en estos listados, en cuanto decisión medio ambiental de ca- 
rácter ejecutivo es una competencia propia de las CCAA que la adopta en base a la información técnica disponible y acomodándose a los criterios fijados por la normativa comunitaria. El Estado no ostenta, en principio, competencias para la clasificación de estos espacios sin perjuicio de que en el ejercicio de su función de coordinación interterritorial pueda adoptar decisiones que incidan en las propuestas elaboradas por las CCAA. Asi lo pone de manifiesto también la Sentencia Tribunal Supremo de 11 de marzo de 2009 al afirmar "Por otra parte, el propio objetivo de la Red y el hecho de que los hábitats naturales y de especies no tengan indefectiblemente que coincidir con las divisiones territoriales-administrativas entre las diferentes Comunidades Autónomas, siendo habitual la existencia de hábitats compartidos por varias de ellas, determina la necesidad de una coordinación superior en aras de esa coherencia que, a nivel nacional, se efectúa por el Ministerio de Medio Ambiente y, a nivel transnacional, por medio de la Comisión. Por tanto, no cabe restar importancia a la labor de la Comisión Europea, calificándola como de mera "validación" de las propuestas aprobadas por las CCAA. La propia Decisión aprobatoria de los ámbitos $L I C$ en la región biogeográfica mediterránea, en su considerando 10, contiene un breve resumen de las labores de comprobación y concertación llevadas a cabo con los Estados miembros del que se deduce la complejidad de esta labor, asi como la conveniencia de su aprobación, a pesar de reconocerse incompleta, para no demorar por más tiempo, la aprobación de la primera lista de LIC en esta región biogeográfica. Todo esto lleva a rechazar que las propuestas que aprueban las CCAA sean vinculantes para la Comisión Europea, o que la propuesta de LIC aprobados por la Junta de Andalucía decida directamente o indirectamente el fondo del asunto, ya que la decisión definitiva solo será adoptada por la Comisión tras las funciones de comprobación indicadas".

De modo que si bien no cabe descartar, a priori, que la resolución del Ministerio de Medio Ambiente, aprobando la propuesta de los listados de interés comunitario remitidos por las CCAA, puede tener sustantividad propia. Como regla general, la decisión de incluir una finca en estos listados y, por lo tanto, la posibilidad de cuestionar los criterios utilizados para ello, especialmente cuando los terrenos y los criterios medioambientales utilizados afecten al ámbito territorial interno de una sola Comunidad Autónoma, deberán cuestionarse con motivo de la impugnación de la resolución adoptada por la Comunidad Autónoma aprobando la propuesta de los LIC. $\Upsilon$ solo cuando el Ministerio de Medio Ambiente, haciendo uso de sus facultades de coordinación y control sobre esta materia, modifique o altere la propuesta elaborada por las CCAA podrá cuestionarse de forma autónoma la sustantividad de la decisión adoptada basándose en la ilegalidad o improcedencia de los criterios correctores adoptados por dicha autoridad estatal.

Esta conclusión no genera indefensión alguna a los afectados pues disponen de la posibilidad impugnar la propuesta elaborada por las CCAA, tal y como ha reconocido la reseñada sentencia del Tribunal Supremo.

La solución contraria, en la que se permitiese cuestionar los criterios de inclusión de una finca en los LIC con motivo de la impugnación del acto emanado del Ministerio de Medio Ambiente, sin que este hubiese modificado ni alterado en modo alguno los criterios de clasificación 
proporcionados por las CCAA, subvertiría el reparto competencial Estado-CCAA establecido por la Constitución y los Estatutos de Autonomía, y en el subsiguiente recurso contencioso el Estado estaría defendiendo la conformidad a derecho de una decisión adoptada por otra Administración pública en el ejercicio de sus competencias y con criterios técnicos ajenos a su propia actuación. Por otra parte, y dado que se podrían impugnar las resoluciones de dos Administraciones públicas diferentes, por los mismos motivos y ante diferentes tribunales (en un caso ante el TSF correspondiente y en otro ante la Audiencia Nacional) se estarían duplicando las vías de impugnación con el consiguiente riesgo de que pudieran dictarse sentencias contradictorias sobre la misma pretensión.

$\Upsilon$ todo ello, con independencia, de la función que cumple el Estado como interlocutor y negociador con la Comisión Europea en el procedimiento destinado a aprobar definitivamente estos listados comunitarios."

Vemos así que se rechaza la recurribilidad independiente del acto del Ministerio de Medio Ambiente, aprobatorio de la propuesta de LICs del Estado español, en los casos en los que el Ministerio se limite a recoger las propuestas de las Comunidades Autónomas, sin introducir modificación alguna en las mismas. De modo que, en tales casos, pasa a considerarse como un mero acto formal de reproducción de las propuestas autonómicas y de mera comunicación, carente de sustantividad propia e independiente de las citadas propuestas autonómicas.

\section{Aspectos procedimentales de esta Etapa Primera: cambio nor- mativo}

Uno de los principales aspectos que ha sido analizado por los Tribunales en relación con el procedimiento administrativo seguido tanto por las Comunidades Autónomas como por el Estado es el relativo a la omisión del trámite de audiencia y de información pública.

El precepto de aplicación, en lo que se refería al procedimiento a seguir era, en un primer momento, el artículo 4 del RD 1995/97, de 7 de diciembre por el que se establecen medidas para contribuir a garantizar la biodiversidad mediante la conservación de los hábitats naturales y de la fauna y flora silvestres, donde nada se contemplaba a respecto.

Como bien se afirma en la Sentencia de la Audiencia Nacional de 23 de septiembre de 2010, antes citada, con ocasión de las propuestas elaboradas durante la vigencia del precepto expuesto:

"No existe ni en la normativa comunitaria ni el derecho nacional precepto alguno, que resulte aplicable por razón temporal al supuesto que nos ocupa, que establezca la exigencia de un 
trámite de audiencia o de un periodo de información pública en el procedimiento destinado a la elaboración de los LIC. Fue la Ley 42/07 de 13 de diciembre, de Patrimonio Natural y de la Biodiversidad (que no estaba vigente al tiempo de los hechos aquí examinados) la que en su artículo 42.2 y respecto a la fase de elaboración de tales listados por parte de las Comunidades Autónomas la que establece que la propuesta que elaboren dichas Comunidades Autónomas "se someterá al trámite de información pública". Sin que tampoco resulten aplicables al respecto los preceptos generales de la Ley $30 / 92$ al existir un procedimiento específico destinado a regular esta materia."

En efecto, es evidente que al no exigir la norma aplicable el cumplimiento de dichos trámites de audiencia o de información pública, no podía exigirse el cumplimiento de los mismos.

De igual forma, se rechaza la exigencia de tales trámites en base a la aplicación supletoria de la Ley 30/92, ya que la existencia de un procedimiento específico regulador de la materia conlleva la exclusión del procedimiento de la Ley 30/92, sin que en base al invocado carácter supletorio quepa realizar una integración de trámites; máxime, si tenemos en cuenta que nos encontramos ante un procedimiento regulado por el derecho comunitario, con distintas etapas, en las que interviene no sólo las Administraciones del Estado y de la Comunidad Autónoma sino también las Instituciones Europeas.

Este criterio se ha visto confirmado, recientemente, por la sentencia del Tribunal Supremo de 8 de julio de 2014, en la que citando la sentencia del Tribunal Supremo de 5 de septiembre de 2013 se afirma

"En cualquier caso, es conveniente observar que la fase de información pública y audiencia previa de la propuesta de LIC se incluyó como novedad en la Ley 42/2007 (artículo 44); y aunque se llevó a cabo en el procedimiento de elaboración de la propuesta de LIC y declaración de ZEPAs, no estaba ni siquiera previsto en el artículo 4 del Real Decreto 1997/1995, que era el aplicable al supuesto enjuiciado.

En este sentido debe recordarse también que el Tribunal de Primera Instancia de la Comunidad Europea (actualmente Tribunal General) rechazó el derecho de los particulares y Ayuntamientos a ser oídos en el procedimiento de la elaboración de la lista de LICs por la Comisión Europea. Así en el auto de 19 de septiembre de 2006 (T-122/05), Benko v. Comisión, se contienen los siguientes fundamentos 68 y 69 :

" 68 A este respecto, según reiterada jurisprudencia, en principio, ni el proceso de elaboración de los actos de alcance general ni dichos actos en sí mismos, exigen, en virtud de los principios generales de Derecho comunitario, como el derecho a ser oído, la participación de las personas 
afectadas, ya que se supone que los intereses de éstas los representan los órganos políticos a los que corresponde adoptar dichos actos (auto del Tribunal de Primera Instancia de 15 de septiembre de 1998, Molkerei Grofbraunshain y Bene Nahrungsmittel/Comisión, T-109/97, Rec. p. 1I-3533, apartado 60, y de 9 de noviembre de 1999, CSR Pampryl/Comisión, T114/99, Rec. p. 11-3331, apartado 50).

69 También se desprende de la jurisprudencia del Tribunal de Fusticia ( sentencia de 14 de mayo de 1998), Windpark Groothusen/Comisión, C-48/96 P, Rec. p. I- 2873, apartado 47; véase también, en este sentido, la sentencia del Tribunal de fusticia de 29 de junio de 1994, Fiskano/Comisión, C-135/92, Rec. p. I-2885, apartados 39 y 40), que el requisito de oir a los interesados antes de adoptar el acto que les concierne sólo se exige cuando la Comisión contempla la posibilidad de aplicarles una sanción o de adoptar una medida capaz de afectar a su situación jurídica. El derecho a ser oído en un procedimiento administrativo que se refiere a una persona específica no puede trasladarse al contexto de un procedimiento legislativo que da lugar a la adopción de medidas de alcance general. La reiterada jurisprudencia en materia de competencia, que exige que las empresas que presuntamente han infringido las normas del Tratado sean oídas antes de que se adopten en su contra medidas, y en particular sanciones, debe apreciarse en su propio contexto y no puede ampliarse al de un procedimiento legislativo comunitario que conduce a la adopción de medidas de carácter legislativo que implican una decisión de política económica y se aplican con carácter general a los operadores afectados ( sentencia del Tribunal de Primera Instancia de 11 de diciembre de 1996), Atlanta y otros/ CE , T-521/93, Rec. p. 11-1707, apartado 70) ".

Además, y para finalizar, la sentencia aborda que en la propuesta impugnada no puede quedar comprometido el que ha venido a denominarse segundo pilar del Convenio de Aarhus, incorporado a la Ley 27/2006, por la que se regulan los derechos de acceso a la información, de participación pública y de acceso a la justicia en materia de medio ambiente, que incorporan las Directivas 2003/4/CE y 2003/35/CE . "El derecho a la participación del público, según el citado Convenio, se extiende a tres ámbitos de actuación pública: la autorización de determinadas actividades, la aprobación de planes y programas y la elaboración de disposiciones de carácter general de rango legal o reglamentario, y ninguno de esos supuestos concurría en el caso examinado, en que la aprobación de los instrumentos de gestión y conservación se adopta en la tercera fase de la creación de la Red [ver. Artículo 3.a) de Ley 42/006.".

Estos pronunciamientos revelan la existencia de un importante cambio normativo en la regulación del procedimiento, tras la aprobación del artículo 44 de la Ley 42/07, momento partir del cual se exige la necesidad de dar trámite de audiencia a los afectados por la propuesta así como la necesidad de someter la misma a trámite de información pública.

Antes de dicho cambio normativo, la no exigencia de estos trámites así como 
la ausencia de publicidad, si bien no afectaba a la legalidad de la propuesta, lo que sí provocaba era una absoluta falta de conocimiento por parte de los interesados del contenido de la citada propuesta, a pesar de los efectos directos que de la misma se derivaban para los terrenos incluidos en ella. Falta de conocimiento que les impedía también poder reaccionar contra la propuesta e impugnarla.

\section{LA APROBACIÓN POR PARTE DE LA COMISIÓN EUROPEA DEL LISTADO DE LUGARES DE IMPORTANGIA GOMUNITARIA}

\section{Alcance y eficacia de la aprobación por parte de la Comisión Europea}

La Sentencia del Tribunal Supremo de 11 de mayo de 2009, si bien, como hemos expuesto, se refiere a las propuestas de las Comunidades Autónomas, lo cierto es que contiene también importantes pronunciamientos sobre el acto aprobatorio del LIC por parte de la Comisión Europea. Así, en el mismo Fundamento de Derecho undécimo ya citado, expone:

El propio ámbito territorial de Red Natura 2000, europeo, y la necesidad de que su configuración cumpla el requisito de "coherente", (según expresión utilizada en el artículo 3.1 de la Directiva 92/43/CE, coherencia que ha de predicarse respecto de todos los Estados obligados a su cumplimiento), determina la necesidad de una examen de conjunto de las propuestas remitidas por cada Estado en función de las diferentes regiones biogeográficas previstas en la Directiva. Este examen de conjunto de los LIC está ausente, por definición, en las propuestas elaboradas por cada Comunidad Autónoma, que se confeccionan de forma independiente por cada una de ellas.

Por otra parte, el propio objetivo de la Red y el hecho de que los hábitats naturales y de especies no tengan indefectiblemente que coincidir con las divisiones territoriales-administrativas entre las diferentes Comunidades Autónomas, siendo habitual la existencia de hábitats compartidos por varias de ellas, determina la necesidad de una coordinación superior en aras de esa coherencia que, a nivel nacional, se efectúa por el Ministerio de Medio Ambiente y, a nivel transnacional, por medio de la Comisión. Por tanto, no cabe restar importancia a la labor de la Comisión Europea, calificándola como de mera "validación" de las propuestas aprobadas por las CCAA. La propia Decisión aprobatoria de los ámbitos LIC en la región biogeográfica mediterránea, en su considerando 10, contiene un breve resumen de las labores de comprobación y concertación llevadas a cabo con los Estados miembros del que se deduce la complejidad de esta labor, asi como la conveniencia de su aprobación, a pesar de reconocerse incompleta, para no demorar por más tiempo, la aprobación de la primera lista de LIC en esta región biogeográfica. Todo esto lleva a rechazar que las propuestas que aprueban las CCAA sean vinculantes para la 
Comisión Europea, o que la propuesta de LIC aprobados por la funta de Andalucía decida directamente o indirectamente el fondo del asunto, ya que la decisión definitiva solo será adoptada por la Comisión tras las funciones de comprobación indicadas.

Asi se deduce con toda claridad de lo dispuesto en el artículo 4.2, párrafos primero y tercero de la Directiva 92/43/CEE, donde se dispone que es la Comisión la que redactará un "proyecto de lista" y la que la aprobará."

Vemos así que la sentencia es clara respecto del papel que corresponde a la Comisión Europea, en cuanto que la misma no se limita a asumir el acto de la Comunidad Autónoma, sino que procede a su análisis y a comprobar su corrección y adecuación a la normativa comunitaria y a las exigencias contenidas en la misma.

De tal manera, que podríamos afirmar que, una vez que se ha superado la etapa 1 y se ha producido la aprobación por parte de la Comisión Europea de un LIC, el acto de propuesta de la Comunidad Autónoma recogida por el Ministerio se ha visto ya sustituido por el acto definitivo dictado por la Comisión Europea, desapareciendo como acto con sustantividad propia de la vida jurídica.

\section{Aprobación e ulteriores actualizaciones del Listado de LICs de la Región Biogeográfica Mediterránea}

Por parte de la Comisión Europea la lista inicial de LIC de la Región Biogeográfica Mediterránea, fue aprobada por Decisión 613 de la Comisión Europea de 19 de julio de 2006.

Así, para dicha Región Biogeográfica Mediterránea, Grecia, España, Francia, Italia, Chipre, Malta, Portugal y el Reino Unido transmitieron a la Comisión entre enero de 2003 y septiembre de 2006, de conformidad con el artículo 4, apartado 1, de la Directiva 92/43/CEE, listas de lugares propuestos como lugares de importancia comunitaria a efectos del artículo 1 de la misma.

Las listas de los lugares propuestos iban acompañadas de información relativa a cada lugar, consignada en el formulario establecido por la Decisión 97/266/CE de la Comisión, de 18 de diciembre de 1996, relativa a un formulario de información sobre un espacio propuesto para su inclusión en la red Natura 2000 .

Después de ser analizada esta información por el Comité de expertos que asesoraba a la Comisión Europea, se procedió a la aprobación de la Lista de LIC. 
Con posterioridad, dicha Decisión ha sido actualizada en cuatro ocasiones. Dicha actualización no se ha llevado cabo mediante la mera modificación de la Decisión inicial sino que se han dictado Decisiones ulteriores que se han ido sucediendo, sustituyendo la nueva a la anteriormente adoptada. Es el caso de Decisiones 2008/335/CE; 2009/95/CE; 2010/45/CE y 2011/85/UE.

Como señala el texto de la citadas Decisiones de la Comisión, en el contexto de una adaptación dinámica de la Red Natura 2000, se revisan las listas de LIC y se ha procedido a actualizar la lista inicial.

Por un lado, la actualización de la lista inicial de LICs para la Región Biogeográfica Mediterránea se hacía necesaria para incluir lugares adicionales a los propuestos desde marzo de 2006 por los Estados miembros como LIC a efectos del artículo 1 de la Directiva 92/43/CEE.

Por otro lado, dicha actualización de la lista inicial de LICs para la Región Biogeográfica Mediterránea era precisa para reflejar los cambios en la información disponible sobre los lugares enviada por los Estados miembros tras la adopción de la lista comunitaria. En ese sentido, las listas actualizadas de LICs vienen a constituirse en una especie de versión consolidada de la lista inicial.

Para la aprobación de la lista actualizada de LIC y respecto de aquellos espacios que no hubieran sufrido alteración o modificación alguna respecto de la información suministrada en la propuesta inicial que dió lugar a la Decisión 2006/613, no era necesaria la tramitación prevista en la Directiva para la aprobación del LIC, es decir, no era necesaria formular nueva propuesta por la Comunidad Autónoma y aprobación previa de la misma por parte del Ministerio para su remisión a la Comisión Europea, limitándose la actuación en este caso a comunicar que se trata de la misma información que provocó la aprobación del LIC en la Decisión 2006/613.

Tan solo se siguió dicho procedimiento, cuando se trataba de terrenos no incluidos anteriormente en el LIC o cuando se trata de una modificación, bien de características o de los límites de un LIC. Es, en estos casos, cuando se tramita nueva propuesta por parte de la Comunidad Autónoma que requiere la previa aprobación de la Administración General del Estado así como la ulterior comprobación por la Comisión Europea para su aprobación en la Decisión que se dicta al efecto, la cual se viene a configurar como una especie de Texto Refundido en el que se incluye el contenido de la Decisión anterior a la que sustituye, junto con las actualizaciones que se formulan que bien suponen la inclusión de nuevos LIC en la lista o la modificación en mayor o menor medida de alguno o algunos de los ya existentes. 


\section{Recurribilidad de la Decisión europea}

Sobre la recurribilidad de la Decisión europea ante los órganos jurisdiccionales comunitarios conviene traer a colación el Auto de 14 de julio de 2008 del Tribunal de Primera Instancia, en el que se inadmite el recurso de anulación planteado por una entidad española contra la Decisión 2006/613/CE de la Comisión, de 19 de julio de 2006, por la que se adopta, de conformidad con la Directiva, la lista de LICs de la Región Biogeográfica Mediterránea. Esta resolución judicial analiza los requisitos para la procedencia del recurso de anulación. Así, en primer lugar, analiza la naturaleza de la Decisión impugnada, afirmando.

24 A tenor del artículo 230 CE párrafo primero, pueden ser objeto de recurso los actos adoptados conjuntamente por el Parlamento Europeo y el Consejo, los actos del Consejo, de la Comisión y del Banco Central Europeo (BCE) que no sean recomendaciones o dictámenes, y los actos del Parlamento Europeo destinados a producir efectos jurídicos frente a terceros.

25 Según reiterada jurisprudencia, es posible interponer un recurso de anulación contra todas las disposiciones adoptadas por las instituciones, cualesquiera que sean su naturaleza o su forma, que tiendan a producir efectos jurídicos (sentencia del Tribunal de fusticia de 31 de marzo de 1971, Comisión/Consejo, 22/70, Rec. p. 263, apartado 42; sentencias del Tribunal de Primera Instancia de 10 de abril de 2003, Le Pen/Parlamento, T-353/00, Rec. p. II1729, apartado 77, y de 5 de abril de 2006, Deutsche Bahn/Comisión, T-351/02, Rec. p. II-1047, apartado 35). Cuando se trata de actos o decisiones cuya elaboración se efectúa en varias fases, principalmente al finalizar un procedimiento interno, de esta misma jurisprudencia se deduce que, en principio, sólo constituyen actos que pueden impugnarse las medidas que fijan definitivamente la postura de la institución de que se trate al finalizar dicho procedimiento, con exclusión de las medidas intermedias cuyo objetivo es preparar la decisión definitiva. Así, las medidas de naturaleza puramente preparatoria, como tales, no pueden ser objeto de un recurso de anulación, si bien las posibles ilegalidades de que estén viciadas pueden ser invocadas en apoyo del recurso dirigido contra el acto definitivo del que constituyen una fase de elaboración (sentencia del Tribunal de Fusticia de 11 de noviembre de 1981, IBM/Comisión, 60/81, Rec. p. 2639, apartados 10 y 12, y auto del Tribunal de Primera Instancia de 2 de junio de 2004, Pfizer/Comisión, T-123/03, Rec. p. II-1631, apartados 22 y 24).

26 En el presente caso, la Decisión impugnada fue adoptada por la Comisión con arreglo al artículo 4, apartado 2, de la Directiva y fija la postura de la Comisión relativa a los lugares de importancia comunitaria que los Estados miembros habian propuesto para la región biogeográfica mediterránea. Así, la adopción de la Decisión impugnada pone fin al procedimiento previsto por la Directiva para elaborar la lista de lugares de importancia comunitaria. La postura de la Comisión en cuanto a estos lugares no requiere la adopción de un nuevo acto para ser definitiva. Además, de esta Decisión se desprenden efectos jurídicos, puesto que, en virtud del artículo 4, apartado 5, de la Directiva, desde el momento en que la Comisión establece la lista 
de lugares de importancia comunitaria, estos lugares quedan sometidos al régimen previsto por el artículo 6 de la Directiva.

27 El hecho de que esta lista pueda revisarse, en virtud del artículo 1, párrafo segundo, de la Decisión impugnada, es irrelevante a efectos de determinar si dicha Decisión puede ser objeto de recurso. Tal revisión únicamente afectará, en su caso, a determinados tipos de hábitats y a determinadas especies designadas en los anexos 2 y 3 de la Decisión impugnada, y no a los lugares de importancia comunitaria ya incluidos en el anexo 1, que incluye el lugar en el que se sitúan las fincas de los demandantes. Además, esta revisión se efectuará mediante la adopción de nuevas decisiones según el mismo procedimiento que prevé la Directiva y que se siguió para la adopción de la Decisión impugnada. Por otra parte, contrariamente a lo que alega la Comisión, la Decisión impugnada constituye una decisión independiente de las decisiones relativas a las demás regiones biogeográficas, tales como las regiones biogeográficas alpina, atlántica y continental, y de las demás medidas que la Comisión está facultada para adoptar en el marco de la red Natura 2000 prevista por la Directiva.

28 En consecuencia, procede estimar que la Decisión impugnada puede, por su naturaleza, ser objeto de un recurso de anulación.

Para que se cumpla el requisito de que un particular resulte directamente afectado, el acto comunitario de que se trate debe surtir efectos directos en su situación jurídica sin permitir ninguna facultad de apreciación a los destinatarios de dicho acto encargados de su aplicación, por tener éste un carácter meramente automático y derivarse únicamente de la normativa comunitaria sin aplicación de otras normas intermedias (véanse las sentencias del Tribunal de Justicia de 5 de mayo de 1998, Dreyfus/Comisión, C-386/96 P, Rec. p. I-2309, apartado 43, y la jurisprudencia citada, y del Tribunal de Primera Instancia de 27 de junio de 2000, Salamander y otros/Parlamento y Consejo, T-172/98 y T-175/98 a T-177/98, Rec. p. II-2487, apartado 52).

En segundo término el Auto procede a examinar el carácter de afectados de los demandantes, exponiendo al respecto que:

36 La Decisión impugnada no contiene ninguna disposición relativa al régimen de protección de los lugares de importancia comunitaria, tales como medidas de conservación o procedimientos de autorización que hayan de seguirse. Se limita a adoptar la lista de lugares de importancia comunitaria en la región biogeográfica mediterránea. La mera inclusión de los lugares en la lista prevista en el anexo 1 de la Decisión impugnada no impone obligaciones a los operadores económicos o a los particulares. Así, al no imponer obligaciones a los propietarios o a los explotadores de los bienes inmuebles de que se trata, no puede considerarse que la Decisión impugnada afecte directamente a sus derechos o al ejercicio de éstos.

37 La Directiva, sobre cuya base se adoptó la Decisión impugnada, obliga al Estado miem- 
bro en cuanto al resultado que debe conseguirse, pero atribuye a las autoridades nacionales la competencia relativa a las medidas de conservación que han de adoptarse y a los procedimientos de autorización que deben tramitarse, aspectos en los que gozan de un margen de apreciación (véanse, en este sentido, los autos del Tribunal de Primera Instancia de 22 de junio de 2006, Freiherr von Cramer-Klett y Rechtlerverband Pfronten/Comisión, T-136/04, Rec. p. II1805, apartados 48 a 53, y de 19 de septiembre de 2006, Benkö y otros/Comisión, T122/05, Rec. p. II-2939, apartados 39 a 45).

38 En efecto, incumbe a los Estados miembros afectados, y no a la Comisión, dar cumplimiento a las obligaciones previstas por el artículo 6 de la Directiva, que, en virtud de su artículo 4, apartado 5, son aplicables a los lugares de importancia comunitaria que figuran en la lista aprobada por la Comisión. Así, corresponde al Estado miembro de que se trate apreciar cuáles son las medidas de conservación necesarias que respondan a las exigencias ecológicas de los tipos de hábitats y de las especies presentes en los lugares en cuestión. El Estado miembro interesado debe asimismo adoptar las medidas que considere apropiadas para evitar el deterioro de los lugares. Le corresponde igualmente evaluar y autorizar, en su caso, los proyectos que puedan afectar a los lugares de manera apreciable, asi como adoptar medidas compensatorias necesarias si, a pesar de las conclusiones negativas de la evaluación, debieran realizarse tales proyectos por razones imperiosas de interés público de primer orden (véanse, en este sentido, los autos Freiherr von Cramer-Klett y Rechtlerverband Pfronten/Comisión, citado en el apartado 37 supra, apartado 52, y Benkö y otros/Comisión, citado en el apartado 37 supra, apartados 40 y 42 a 45).

39 Por tanto, como reconocen indirectamente los propios demandantes, al referirse a la legislación nacional que prevé medidas de protección aplicables a los lugares de importancia comunitaria, las disposiciones nacionales que adaptan el Derecho interno a la Directiva, y no la Decisión impugnada, son las que pueden producir efectos jurídicos sobre la situación de los demandantes. El hecho de que las autoridades nacionales hayan adoptado ya medidas en virtud de la Directiva que se aplican a los lugares incluidos en la lista de lugares de importancia comunitaria de la Decisión impugnada no implica que el margen de apreciación del que dispone el Reino de España para la puesta en práctica de la Directiva y de la Decisión impugnada sea meramente teórico, pues no puede excluirse que las autoridades españolas adopten otro tipo de medidas tras la Decisión impugnada.

40 De lo anterior resulta que no cabe considerar que los demandantes estén directamente afectados por la Decisión impugnada. Dado que los requisitos de admisibilidad establecidos en el artículo 230 CE, párrafo cuarto, son acumulativos, procede declarar la inadmisibilidad del presente recurso sin necesidad de examinar si los demandantes resultan individualmente afectados por la Decisión impugnada

Esta resolución fue recurrida en casación ante el Tribunal de Justicia de la Unión Europea que en su sentencia de 23 de septiembre de 2009 desestimó el recurso de casación, y confirmó así la imposibilidad de que los particulares puedan 
acudir al recurso de anulación para impugnar la Decisión europea de aprobación de LICs. Y ello, por no considerar a los titulares de los terrenos incluidos como directamente afectados, dado que la Decisión no procede a imponer obligaciones ni contiene ninguna disposición relativa al régimen de protección de los lugares de importancia comunitaria, tales como medidas de conservación o en su caso los procedimientos de autorización que hayan de seguirse para procurar la salvaguarda de los valores medioambientales que se pretenden proteger con la aprobación del LIG.

Con ello, parece privar a la Decisión de una sustantividad propia al tratar de diferir la posible impugnación a la que se pueda llevar a cabo frente a los actos que se dictan en la tercera y última Etapa.

\section{DEGLARAGION DE ZONAS DE ESPECIAL PROTEGGIÓN}

En la tercera y última etapa del procedimiento de declaración de LICs son de nuevo los Estados Miembros los que actúan en orden a lograr la protección medioambiental perseguida por la Directiva 92/43/CEE.

En esta Etapa como señaló el Auto del Tribunal de Primera Instancia antes señalado, corresponde al Estado miembro de que se trate apreciar cuáles son las medidas de conservación necesarias que respondan a las exigencias ecológicas de los tipos de hábitats y de las especies presentes en los lugares en cuestión. El Estado miembro interesado debe asimismo adoptar las medidas que considere apropiadas para evitar el deterioro de los lugares. Le corresponde igualmente evaluar y autorizar, en su caso, los proyectos que puedan afectar a los lugares de manera apreciable, así como adoptar medidas compensatorias necesarias si, a pesar de las conclusiones negativas de la evaluación, debieran realizarse tales proyectos por razones imperiosas de interés público de primer orden.

En el caso de España, hay que tener en cuenta la regulación contenida, en un primer momento, en los artículos 5 y 6 del Real Decreto 1997/95, luego sustituida por los artículos 44 y 45 de la Ley 42/07.

El artículo 5 del RD 1997/5 traspone la Directiva, señalando a la Comunidad Autónoma como la Administración competente para proceder a la declaración de las zonas especiales de conservación lo antes posible y como máximo en un plazo de seis años desde la declaración del LIC.

Por su parte el artículo 44 introduce mayor detalle sobre tal actuación de la Comunidad Autónoma, declarando Las Comunidades autónomas, previo procedimiento 
de información pública, declararán las Zonas Especiales de Conservación y las Zonas de Especial Protección para las Aves en su ámbito territorial. Dichas declaraciones se publicarán en los respectivos Diarios Oficiales incluyendo información sobre sus límites geográficos, los hábitats y especies por los que se declararon cada uno. De ellas se dará cuenta al Ministerio de Medio Ambiente a efectos de su comunicación a la Comisión Europea, de conformidad con lo establecido en el artículo 10 de la Ley 30/1992, de 26 de noviembre, de Régimen Furídico de las Administraciones Públicas y del Procedimiento Administrativo Común.

Tanto el artículo 6 del RD 1997/95 como el artículo 45 de la ley 42/07 con idéntico contenido se refieren a las medidas de conservación, a los planes de gestión que deben aprobarse así como a la adopción de medidas tanto preventivas como compensatorias para garantizar la protección del espacio de la Red ecológica europea Natura 2000.

Son estos instrumentos normativos aprobados por las Comunidades Autónomas los que fijan el régimen jurídico concreto a que se someten los terrenos incluidos en el LIC. De ahí que resulte clara la recurribilidad de los mismos.

No obstante hay que poner de relieve que las autoridades nacionales, en el ejercicio de la competencia relativa a las medidas de conservación que han de adoptarse y a los procedimientos de autorización que deben tramitarse, gozan de un importante margen de apreciación. Margen de discrecionalidad técnica que no exime de la posible revisión jurisdiccional de los instrumentos normativos aprobados a tal efecto. Exigiendo los Tribunales, al igual que sucede con otros instrumentos de planificación medioambiental, la existencia de motivación y justificación suficiente de las medidas concretas que se adopten.

En este sentido, se pronuncia el Tribunal Supremo en su sentencia de 16 de octubre de 2014, en la que estima el recurso de casación formulado contra sentencia del Tribunal Superior de Justicia de Madrid que desestimaba el recurso contencioso administrativo interpuesto por Ecologistas en Acción contra Decreto por el que se declaraba Zona Especial de Conservación (ZEC) " y se aprobaba el Plan de Gestión del Espacio Protegido Red Natura 2000.

En esta sentencia, el Tribunal Supremo, analiza la importancia de la existencia de una motivación suficiente justificativa, tanto de la zonificación como de las medidas de protección concreta y gestión que se contienen en las normas por las que se procede a declarar una Zonas de Especial Conservación (ZEC).

Así, pone de manifiesto la importancia de que en el expediente consten informes, documentos o dictámenes en los que quede plasmada la ponderación de intereses derivados del correcto ejercicio de la potestad planificadora, ni la forma 
en que se ha tenido en consideración las "exigencias ecológicas" de los objetivos de conservación a los que sirve la declaración del lugar tal y como los exige el artículo 45 de la Ley 42/2007, del Patrimonio Natural y de la Biodiversidad y la normativa comunitaria.

Asimismo declara que en los casos en los que se denuncie la falta de motivación del Plan, correspondía la Administración actuante acreditar que en el instrumento aprobado estaban debidamente definidos los objetivos de conservación específicos a los requerimientos ecológicos de los hábitats y especies de interés comunitario y, asimismo, que estaban debidamente justificados los criterios de zonificación y el establecimiento de medidas de conservación y de gestión. Considera así que ante la falta de motivación no puede hacerse recaer la carga de la prueba en la parte recurrente, en el sentido de exigir a ésta una prueba pericial exhaustiva acreditativa de la arbitrariedad de la decisión del planificador. En este sentido recoge:

"No puede asumirse la afirmación que se hace en la sentencia de instancia de que "sólo las pruebas periciales" son instrumento adecuado para dirimir cuestiones como las que se suscitaban en el proceso. Si la recurrente denunciaba la falta de motivación y arbitrariedad en la zonificación y en el establecimiento de medidas de gestión, correspondía a la Administración poner de manifiesto la existencia de tal justificación señalando a tal efecto en qué concretos informes o documentos se encontraban razonada y motivada la zonificación y el establecimiento de medidas de gestión. $Y$, desde luego, en ningún caso cabe reprochar a la parte recurrente el que no se hubiesen incorporado a las actuaciones los trabajos técnicos previos en los que "presumiblemente" -según la Sala de instancia- se encontraría esa justificación que ha quedado sin acreditar."

No resulta por tanto cuestionable la posibilidad de impugnar las medidas de protección adoptadas al declararse ZEC y que los órganos judiciales analicen la corrección de las mismas. Cuestión distinta es que se acuda a la impugnación de estos Decretos como vía, no tanto para cuestionar el régimen de protección y plan de gestión que se aprueba sino para impugnar los límites geográficos, los hábitats o especies por los que se declaró el LIC, lo cual si bien constituye a la luz del artículo 44 de la Ley 42/07 contenido obligado del Decreto se trata de aspectos en los que el mismo se limita a reproducir la Decisión Europea de aprobación del LIC que constituye presupuesto necesario para la declaración ZEC.

\section{REFLEXIONES SOBRE LA REGURRIBILIDAD DE LA IN- GLUSION DE UNOS TERRENOS DENTRO DE UN LUGAR DE IMPORTANGIA GOMUNITARIA}

$\mathrm{Al}$ hilo de lo expuesto y teniendo en cuenta los pronunciamientos judiciales analizados, realizaremos una serie de reflexiones sobre las vías para poder im- 
pugnar la inclusión de unos terrenos dentro de un LIC, en atención a las distintas etapas del procedimiento y su relación entre sí.

Los pronunciamientos a los que hemos aludido, son claros sobre la recurribilidad de las propuestas LIC elaboradas por la Comunidades Autónomas, sobre el carácter meramente formal de la propuesta que eleva el Ministerio a la Comisión Europea, recogiendo las propuestas autonómicas, sobre la falta de legitimación de los particulares para impugnar directamente la Decisión comunitaria de aprobación del LIC así como sobre el objeto de los recursos interpuestos contra los Decretos de declaración de ZEG.

Los distintos pronunciamientos se han referido a la recurribilidad de cada uno de los actos que, en el seno de este procedimiento claramente complejo, se dictan por las distintas Administraciones intervinientes, pero en ninguno de ellos se ha abordado la recurribilidad desde la perspectiva del procedimiento en su conjunto y el derecho a la tutela judicial efectiva del que son titulares los interesados afectados por la declaración de un LIC.

En este sentido hemos de partir de la recurribilidad de la propuesta de LIC que es formulada por las Comunidades Autónomas, reconocida en la sentencia de 11 de mayo de 2009 del Tribunal Supremo. No obstante, debe ponerse de manifiesto que si bien dicha sentencia es clara sobre la recurribilidad de la propuesta en atención a su naturaleza y alcance, lo cierto es que no aborda determinadas cuestiones planteadas en la instancia.

En efecto, encontramos que la sentencia estima recurso de casación frente Auto de 1 de diciembre de 2006 por el que la Sala de lo contencioso administrativo del Tribunal Superior de Justicia de Andalucía, con sede en Sevilla, declaró inadmisible el recurso contencioso administrativo interpuesto contra la resolución de fecha imprecisa, en virtud de la cual se aprobó por parte de la Junta de Andalucía Propuesta de LIC. Y ello, por considerar que no se trataba de una actuación administrativa susceptible de impugnación autónoma, puesto que el listado definitivo por quién se remite es por el Estado y, especialmente, porque la aprobación definitiva corresponde a la Comisión Europea. Además, se basa en el hecho de que por la actora no se razonó cómo quedaba con el presente recurso impugnada la referida aprobación definitiva que, en esas fechas, ya había tenido lugar, en virtud de la Decisión de la Comisión Europea publicada en el DOCE de 21 de septiembre de 2006.

Dicho Auto de inadmisión se vió confirmado por Auto de 26 de febrero de 2007 desestimatorio del recurso de súplica interpuesto contra el mismo, en el que en la misma línea la Sala aprecia que "la mayor acreditación de la procedencia de tal 
inadmisión del recurso deviene de que, no obstante su interposición, los actos de aprobación de los Lugares de Interés Comunitario permanecen inimpugnados e incólumes."

Ninguna de estas cuestiones, es sin embargo abordada por la sentencia del Tribunal Supremo, a pesar de que constituía el principal argumento sobre el que apoyaba el Tribunal de instancia la inadmisibilidad del recurso. El Tribunal Supremo se limitó a analizar la naturaleza y alcance de la Propuesta LIC por la Comunidad Autónoma pero sin entrar a examinar la relación de este acto con los otros actos posteriores que ya se habían dictado en el seno del procedimiento, el cual había superado en aquel momento la segunda etapa.

Y es que, debe recordarse que una vez que se ha superado la Etapa 1 y se ha producido la aprobación por parte de la Comisión Europea de un LIC, el acto de propuesta de la Comunidad Autónoma se ha visto sustituido por el acto definitivo dictado por la Institución Europea, desapareciendo como acto con sustantividad propia de la vida jurídica.

Y, es por ello, por lo que si bien es recurrible la propuesta, carece sin embargo de virtualidad la anulación de la propuesta autonómica que, como tal, ya no produce efecto alguno, siendo ahora la aprobación europea del LIC la que produce los efectos.

De tal forma que, no resulta admisible considerar la impugnación de la propuesta elaborada en su día por la Comunidad Autónoma como la vía para poder obtener tanto la anulación de la aprobación del LIC efectuada por la Comisión como una modificación de los límites del LIC y la exclusión del mismo de determinados terrenos.

Así, debe insistirse, en la línea que lo hace el Tribunal Supremo, en la ya citada sentencia de 11 de mayo de 2009, en el hecho de que la aprobación del listado LIC por parte de la Comisión no era meramente "superficial", la Comisión no se encontraba vinculada por las propuestas de los Estados Miembros. De hecho, la aprobación de ese listado vino precedida, por un largo y complejo periodo de coordinación técnica por parte de las instituciones comunitarias, siendo dicha aprobación el resultado de un estudio y análisis pormenorizado de los datos presentados por los Estados Miembros en orden a determinar la adecuación de los mismos al contenido de la Directiva.

Por tanto, no siendo la aprobación del LIC una mera asunción de la propuesta autonómica, no puede considerarse que la pretendida anulación de esta conlleve también la de aquella. Así, teniendo en cuenta la falta de legitimación declarada por el Tribunal de Justicia de las Comunidades Europeas, en lo que se 
refiere a la impugnación por los propietarios de la aprobación del LIC, habría que plantearse una vez superada la Etapa Primera a que vía ha de acudirse y contra qué acto habría que reaccionar para poder cuestionar la inclusión de un terrenos dentro de un LIC.

Estas reflexiones presentan especial relevancia si se tiene en cuenta el hecho de que la ausencia de trámite de audiencia, información pública y publicidad de las propuestas LIC elaboradas en los años 90, ha llevado a que dichas propuestas no fueran impugnadas en su día sino que lo han sido en fechas recientes y posteriores a la aprobación por parte de la Comisión del Listado de LICs de la Región Biogeográfica Mediterránea e incluso a la aprobación de ulteriores actualizaciones del citado listado y a la declaración ZEC.

En estos casos encontramos que, se está pretendido la anulación de un acto que ya no existe en el mundo jurídico, careciendo por tanto el recurso contencioso administrativo materialmente de objeto.

A ello habría que añadir, además, que en la mayor parte de estos recursos contencioso administrativo la pretensión se centra principalmente en una modificación de los límites del LIC en la parte que afecta a la finca de la entidad recurrente, pero una vez aprobado el LIC por la Comisión Europea, la Comunidad Autónoma carece de competencias para alterar los límites del LIC.

Por tanto, es evidente que para la satisfacción de la pretensión ejercitada, ésta no es la vía, ya que un pronunciamiento sobre la propuesta inicial, analizada y ratificada por la Comisión, en modo alguno va a alcanzar la finalidad pretendida. Y es que, si se carece de legitimación para pedir su anulación no procede que por la vía indirecta de impugnación del acto de trámite ya inexistente se anule un acto de una Institución Europea, máxime si tenemos en cuenta que dicha Institución no se encuentra vinculada ni obligada al cumplimiento de las resoluciones judiciales de los Tribunales de los Estados Miembros.

Estos argumentos sin embargo, han sido rechazados por la Sala de lo contencioso administrativo del Tribunal Superior de Justicia de Andalucía, con sede en Sevilla, en recientes sentencias, entre las que podemos señalar, la sentencia de 19 de enero de 2012 (recurso contencioso administrativo 195/06), la sentencia de 15 de noviembre de 2012 (recurso contencioso administrativo 883/09) y la sentencia de 14 de octubre de 2014 (recurso contencioso administrativo 777/11).

En todos estos pronunciamientos la Sala se hace eco del contenido de la tantas veces citada sentencia del Tribunal Supremo de 11 de mayo de 2009 y alude a la impugnabilidad de la propuesta LIC elaborada por la Comunidad Autóno- 
ma desde la perspectiva del derecho a la tutela judicial efectiva. Pero lo cierto es que, con tales afirmaciones, no se da respuesta al problema que planteamos.

Habría que recordar que el derecho a la tutela judicial efectiva, al que aluden las sentencias, implica no solo el derecho a acceder a los órganos judiciales y obtener un pronunciamiento sobre el fondo de la cuestión que se plantea, sino que, como ha reconocido de forma reiterada la jurisprudencia constitucional, supone también el derecho a que el fallo judicial se cumpla y que el interesado sea repuesto en su derecho. De igual forma, son numerosos los pronunciamientos judiciales que han revelado que este derecho fundamental no puede ser interpretado como un derecho ilimitado a acceder a los tribunales al margen de las leyes materiales y procesales.

Pues bien, en estos casos, como hemos señalado, los particulares impugnan los límites del LIC y la inclusión dentro de los mismos de terrenos de su titularidad, solicitando que se anule la propuesta y, con ello, que se excluyan del LIC determinados terrenos.

Por tanto, resultando incontrovertido que la propuesta LIC impugnada ya no existe en mundo jurídico y que en su lugar es la Decisión 613 de la Comisión Europea la que produce sus efectos respecto de los límites del LIC, es evidente que la modificación que la sentencia de instancia de instancia puede llevar a cabo de los límites del LIC de estimarse la pretensión, en modo alguno se puede llevar a efecto, ya que lo que anula la sentencia es una propuesta que ya no produce efectos, por lo que sus eventualidades carecen de virtualidad alguna, al existir un acto de aprobación del LIC por parte de la Comisión Europea que no se ha visto afectado.

En efecto, la nulidad de un acto que ya desplegó toda su eficacia y no existe en el mundo jurídico carece de toda virtualidad. Y, en este sentido, debe destacarse que en caso de dictarse sentencia estimatoria de la pretensión ejercitada nos encontraríamos con un pronunciamiento judicial en el que se condena a una Administración, la Comunidad Autónoma que carece de competencias para alterar los límites de un LIC y que, en cumplimiento de una sentencia que lo ordenara, tan solo podría dar traslado a la Comisión Europea, la cual no se vería obligada a dar cumplimiento a dicha sentencia.

Con estos datos, es claro que la invocación del derecho a la tutela judicial efectiva, no puede constituir un argumento suficiente para enervar la conclusión natural a la que conducen las premisas expuestas, ya que la negación de la pérdida de objeto no obsta a la ausencia de total eficacia del fallo dictado, en cuanto que el mismo afecta a un acto que produjo efectos en su día, pero que, ya al tiempo 
de interponerse este recurso, no producía efecto alguno sino que es otro acto distinto el que produce los efectos que se pretenden evitar con el recurso.

En esta línea se pronuncia la Sala de lo contencioso administrativo del Tribunal Superior de Justicia de Andalucía, con sede en Granada en su sentencia de 27 de octubre de 2014 (recurso contencioso administrativo 2063/09), en cuyo fundamento de derecho segundo in fine recoge que "ningún sentido tiene impugnar el acto de trámite, aunque sea cualificado, cuando ya se terminó el procedimiento mediante la Decisión de la Comisión Europea de 19 de julio de 2006, por lo que, aun admitiendo a efectos puramente dialécticos que se pudiera acordar la nulidad solicitada y la retroacción de las actuaciones administrativas, tal declaración carecería de incidencia material sobre aquella Decisión Adoptada por el órgano competente comunitario, ya que este acto comunitario solo podría ser controlado en cuanto a su legalidad por el Tribunal de Justicia de la Unión Europea, para cuya función los Tribunales nacionales de los Estados Miembros carecen de jurisdicción."

Así, descartada la vía de la impugnación de la propuesta LIC elaborada por las Comunidades Autónomas para lograr la exclusión de determinados terrenos de un LIC, cuando ya se haya producido la declaración del LIC, habría que preguntarse si cabría reconducir la pretensión anulatoria a la impugnación que los interesados puedan dirigir contra los actos concretos que, respecto de la finca incluida en el LIC, se adopten por las distintas Administraciones Públicas en la Etapa 3.

De hecho, resulta incontrovertida la recurribilidad de los Decretos de aprobación de ZEC (Zona Especial de Conservación), al igual que, lo es la el resto de disposiciones o normas que incidan directa o inmediatamente en los derechos de los particulares. La propia jurisprudencia comunitaria a la que hemos aludido, al abordar la posible interposición de recurso de anulación contra Decisión comunitaria por parte de los propietarios parece reconducir la posible impugnación a la que se formule contra la aprobación de los ZEC, al ser estos los actos que producen efectos directos sobre la titularidad de los derechos de los particulares.

No obstante, la duda, no resuelta por los Tribunales, se centraría en determinar si, al impugnar dichos Decretos de declaración de ZEC, los particulares tan solo pueden atacar el régimen concreto de usos y autorizaciones o pueden ir más allá y cuestionar la propia inclusión de los terrenos dentro del LIC.

Si atendemos al hecho de que conforme a las exigencias de la normativa interna de aplicación el Decreto de declaración de ZEC debe contener necesariamente una clara descripción de los límites del LIC, podríamos considerar que se podría impugnar este aspecto al formar parte de su contenido.

Sin embargo, si atendemos al reparto competencial entre las distintas Admi- 
nistraciones intervinientes en el procedimiento así como al hecho de que las Directivas otorgan un papel esencial a la Comisión Europea en la aprobación del LIC, llegaríamos a la solución contraria en la medida en que el Decreto ZEG no estaría innovando en este aspecto, sino que se habría limitado a reproducir el acto de la Comisión Europea.

Y, en este punto, la cuestión se centraría en determinar, si podría considerarse que, al igual que hemos mantenido que una vez adoptada la Decisión comunitaria desaparece del mundo jurídico la propuesta del Estado Miembro, una vez culminada la $3^{\circ}$ Etapa del procedimiento debe entender que ha desaparecido ya del mundo jurídico la Decisión comunitaria de declaración de LIC. A nuestro entender sin embargo, dicha equiparación entre ambos momentos del procedimiento no resulta posible, ya que la relación existente entre la propuesta del Estado y la aprobación del LIC no es la misma que existe entre esta aprobación y la ulterior declaración de ZEC. De modo que, si bien es clara la sustitución de la propuesta por la aprobación del LIC, la declaración de ZEC no viene a sustituir la aprobación de LIC sino que tomándola como presupuesto necesario, parte de su delimitación y de los valores que se declaran protegidos para proceder a desarrollar un régimen adecuado para lograr, en todo el territorio delimitado como LIC, la adecuada protección de los hábitats y especies dignas de protección, a través de la concreción de un régimen de usos y autorizaciones. La relación es, por tanto, de colaboración en cuanto que ambos actos se complementan entre sí, no pudiéndose afirmar que la declaración de ZEC desplace totalmente la eficacia y virtualidad de la Decisión Comunitaria.

Así, desde esta perspectiva debe negarse la posibilidad de que se cuestione la inclusión de unos terrenos dentro de un LIC a través de la impugnación de la declaración de ZEC. No obstante, a diferencia de lo exponíamos en relación a la propuesta de LIC, podríamos mantener que, a pesar de negar tal posibilidad, quedaría garantizado el derecho a tutela judicial efectiva, si tenemos en cuenta que la mera declaración de un LIC no produce por sí misma efectos sobre la esfera de derechos de los particulares y que dichos efectos no que se fijan y concretan en dicha declaración de ZEC y que las medidas concretas que se fijan para un terreno determinado sí sería posible impugnarlas y, en su caso, obtener sentencia judicial anulando las mismas.

En base a todo lo expuesto, podemos concluir que en los casos en los que no se impugnó en su momento la propuesta LIC elaborada por la Comunidad Autónoma no existen vías judiciales para que los particulares puedan lograr, una vez de superada la $1^{\text {a }}$ Etapa del procedimiento la exclusión de unos terrenos dentro de un LIC, pudiéndose tan solo cuestionar los efectos concretos que para esos terrenos se deriven de tal inclusión, los cuales no se concretan hasta la Etapa $3^{\text {a }}$. 
Por ello, ha resultado tan trascendental en orden a la tutela judicial efectiva, el cambio normativo operado por la Ley $42 / 07$, respecto de los aspectos procedimentales de la propuesta de las Comunidades Autónomas, en el sentido de incluir el necesario trámite de audiencia a los afectados y de información pública. Ya que, al garantizar el conocimiento de la propuesta por parte de los interesados, viene a permitir, en el caso de nuevas propuestas, la posibilidad de que se impugnen los límites y la información contenida en la propuestas, cuando todavía no se ha superado la Etapa $1^{\text {a }}$ y que se pueda así, en su caso, obtener un pronunciamiento judicial eficaz sobre estos extremos. 